\title{
CONSIDERAÇÕES SOBRE A UTILIZAÇÃO DO V.L.F. (VERY LOW FREQUENCY) NA PROSPECÇÃO DE ÁGUA SUBTERRÂNEA NOS ESTADOS DA BAHIA E CEARÁ
}

\author{
R.M.Marques ${ }^{1} \&$ N.Ellert ${ }^{2}$
}

PALAVRAS-CHAVE: geofísica aplicada; prospecção de água subterrânea; recursos hídricos em rochas cristalinas.

MARQUES, R.M.; ELLERT, N. (1996) Consideraçð̃es sobre a utilização do V.L.F. (Very Low Frequency) na prospecçăo de água subterrânea nos Estados da Bahia e Ceará. Bol.IG-USP. Sér.Cient. 27:119-136.

\section{RESUMO}

A prospecção de água subterrânea em rochas cristalinas concentra-se na identificação da presença e locaçăo no campo de zonas de fraturas como sendo os locais mais favoráveis à perfuração de poços. Dentre os vários métodos geofísicos utilizados neste tipo de tarefa, optou-se pelo uso do método do VLF (Very Low Frequency). Neste trabalho estão relatados os resultados obtidos em levantamentos executados na Bahia e no Ceará. Os levantamentos executados na Bahia tiveram por finalidade correlacionar os dados de VLF com os dados de poços anteriormente perfurados (poços secos, com água doce e com’ água salgada).

A campanha geofisica no Ceara teve por finalidade obter dados que permitissem locar poços profundos que em seguida foram perfurados para fins de abastecer granjas, indústrias e comunidades urbanas.

Considerando-se a intensidade e assinatura das anomalias obtidas não é possível correlacioná-las com a qualidade da água.

Tomando-se com base nos dados obtidos pela perfuração dos poços no Ceará, verifica-se que com os levantamentos geofisicos realizados, obteve-se um grau de acerto relativamente elevado quando à estrutura (falha) locada.

\begin{abstract}
Groundwater prospection in crystalline rocks concentrates mostly on identifying the presence and location in the field of fractures as being the most suitable sites for drilling deep wells. Among the several available geophysical methods used for this kind of investigation, this paper describes the use of the VLF (Very Low Frequency) method in the states of Bahia and Ceará, northeast Brazil. In Bahia the geophysical work was carried out on existing dry, salt water and potable deep-wells in order to correlate both geophysical and hydrogeological data. In Ceara the VLF survey was used to locate the most favorable points to be drilled. Deep wells were constructed to supply drinking water to farms, industries and urban communities.
\end{abstract}

The results obtained so far in Bahia barely show any direct correlation between the

\footnotetext{
'Aluno Pós-Graduando, IG/USP.

${ }^{2}$ Departamento de Geologia Econômica e Geofísica Aplicada, Instituto de Geociências/USP, Sæ̃o Paulo, Brasil.
} 
geophysical and hydrogeological data of the drilled deep-wells. In Ceará the results of the drilled deepwells at the located structures may conclude for a high rate of certitude.

\section{INTRODUÇÃO}

As rochas cristalinas, dada sua alta compacidade e, portanto baixo grau de porosidade original, são pouco favoráveis a serem portadoras de água subterrânea. Entretanto, quando estas rochas são submetidas a esforços e tensões, causadas por eventos geotectôni$\cos$, originam-se estruturas como falhas e fraturas que, por sua vez, são passiveis ao armazenamento de água subterrânea.

O Nordeste Brasileiro possui grande parte de sua superficie formada por rochas cristalinas. Nestas áreas encontram-se cidades de porte apreciável, que por condições geológicas e climáticas, freqüentemente fazem uso do represamento de águas (açudes, barragens, etc.) como sua única fonte de abastecimento.

O longo período de estiagem (1989-1993), pelo qual passou o NE do Brasil, não permitiu que o represamento das águas fosse em volume suficiente para o abastecimento de cidades, causando assim uma grande procura por fontes alternativas e, em muitos casos, definitivas de abastecimento. A alternativa encontrada, que necessitava de estudos mais apurados, foi o sistema de abastecimento através da locação e perfuração de poços tubulares profundos para estes centros mais necessitados.

Para que fossem diminuídos os riscos de insucessos na construção dos poços, foi necessário introduzir técnicas de prospecção geofísica e, entre as várias técnicas já existentes, optou-se pela utilização da técnica do método do VLF.

A técnica do VLF de prospecção geofísica é bastante indicada, dadas as condições geológicas do NE em especial no Estado do Ceará, onde $70 \%$ da área do Estado é formada por rochas cristalinas, com um manto de alteração pouco espesso, o que viabiliza a utilização desta técnica.

Os levantamentos realizados no Estado da Bahia, tiveram por objetivo calibrar a metodologia, correlacionar as anomalias geofísicas encontradas com os resultados de poços já previamente perfurados, bem como revelar as eventuais causas dos insucessos dos poços perfurados (secos).

Os levantamentos executados no Estado do Ceará foram realizados com o intuito de complementar o abastecimento de água do Município de Maracanaú. Estes levantamentos possuem características diversas em relação aos seus componentes geológicos (espessura do manto de intemperismo) e fisicos locais (distância de zonas habitadas, redes de eletricidade, asfalto, etc.).

\section{OBJETIVOS}

Este trabalho tem por objetivo geral apresentar os resultados obtidos na aplicação do método geofísico VLF, para complementar os estudos hidrogeológicos realizados para locação de poços tubulares profundos, em zonas de rochas cristalinas.

Tendo em vista que normalmente existem dificuldades na locação de poços tubulares em zonas de rochas cristalinas, pretende-se demonstrar a aplicabilidade de uma metodologia que auxilie no processo de locação de estruturas favoráveis ao armazenamento de água subterrânea em áreas que apresentem uma camada de cobertura não muito espessa, notadamente na região nordeste do Brasil.

Os objetivos específicos foram:

- localizar as estruturas favorá- 
veis ao armazenamento de águas subterrâneas;

- tentativa de estabelecer uma correlação entre a anomalia geofísica encontrada no campo e a qualidade da água da perfuração do poço profundo.

Este estudo foi fortemente motivado pelo grande número de insucessos havidos durante a perfuração, conseqüência de uma infeliz locação de poços em estruturas supostamente portadoras de água subterrânea.

\section{METODOLOGLA DE ESTUDO}

Para que os objetivos acima citados pudessem ser alcançados, procurouse estabelecer uma metodologia de campo e interpretativa durante a execução dos trabalhos que constou inicialmente de:

- determinação de áreas piloto para efetuar testes e calibração da metodologia;

- seleção de áreas novas através de cartas topográficas, mapas geológicos e imagens de satélites para identificação de locais com provável presença de estruturas;

- levantamento geofísico, interpretação e correlação dos dados de campo com dados de poços perfurados anterior e posteriormente;

- avaliação dos fatores intervenientes durante a execução dos levantamentos e;

- a partir dos resultados obtidos, fazer recomendações para otimização da metodologia.

\section{O MÉTODO DO VLF - FUNDA- MENTOS}

A idéia da utilização de sinais de rádio em trabalhos de prospecção geofisica não é nova. Medidas de atenuação e polarização do campo eletromagnético indutivo foram feitas por Hack em 1908 e Feldman em 1933 (Heiland,
1946 apud Paterson \& Ronka, 1971) em várias situações geológicas.

$\mathrm{Na}$ Europa a utilização dos métodos que empregavam freqüências de rádios no subsolo com o intuito de investigar a distribuição de correntes induzidas por um corpo condutivo, eram utilizados para mapear jazidas de carvão bem como na exploração de corpos metálicos.

A despeito destas e outras atividades, os métodos que empregavam rádio freqüência não foram muito aceitos nas rotinas de campo ou levantamentos aéreos até que a Geonics Limited introduziu no ano de 1964 um instrumento "passivo" trabalhando com frequêencias nos intervalos de 15 a $25 \mathrm{kHz}$, onde os sinais de rádio transmitidos por antenas militares, para fins de comunicação com submarinos situadas ao redor do mundo, seriam as responsáveis por gerar o sinal primário, exercendo assim o papel de transmissores. No final de 1966 o método havia ganho uma popularidade muito grande o que ocasionou, no ano de 1967 , o surgimento de vários sistemas semelhantes.

As ondas VLF (15 - $30 \mathrm{kHz})$ são emitidas a partir de antenas, que se encontram espalhadas em diferentes lugares do mundo (Fig. 1). Estas antenas transmissoras formam um dipolo elétrico que gera campos elétricos e eletromagnéticos.

Atualmente várias empresas, tais como GEONICS, ABEM, EDA, SCINTREX, etc., fabricam equipamentos que empregam esta metodologia, contribuindo assim para uma rápida evolução dos equipamentos e da metodologia, incorporando a tecnologia utilizada em microprocessadores.

Quando um transmissor de ondas eletromagnéticas gera um campo de força, estas atingindo um corpo condutor, provocam neste corpo o aparecimento de correntes elétricas secundárias induzidas. Estas correntes, por sua vez, 


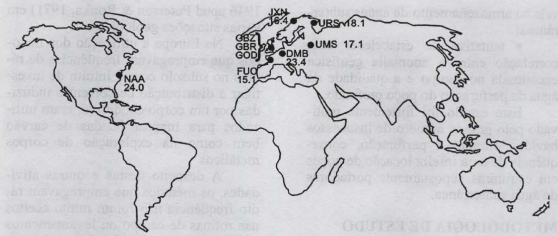

Figura 1 - Localização das principais antenas transmissoras no redor do mundo (ABEM).

criam novos campos eletromagnéticos indutivos, conhecidos como campos eletromagnéticos secundários, que se diferem do campo original emitido tanto na intensidade como fase e direção.

Ao contrário de todos os métodos elétricos existentes, os métodos eletromagnéticos medem diretamente as componentes do campo magnético associado a um fluxo de corrente no subsolo.

A técnica do VLF (Very Low Frequency), assim como as demais técnicas utilizadas nos Métodos Eletromagnéticos (EM) de exploração geofisica, utiliza como base teórica o processo acima descrito, que é conhecido como princípio de "Indução Eletromagnética".

A onda eletromagnética gerada a partir da antena transmissora consta de três componentes, sendo duas componentes horizontais e uma axial. Paralela ao plano de propagação das ondas há uma componente do campo elétrico (Ex), uma componente tangencial pertencente ao campo magnético ( $\mathrm{Hy}$ ) e uma componente vertical que descreve o campo elétrico (Ez) (Fig. 2).

Considerando-se um corpo condutor de forma tabular com propriedades fisicas contrastantes em relação à rocha encaixante, disposto verticalmen-

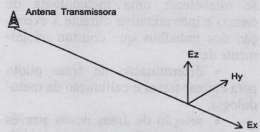

Figura 2 - Componentes de uma onda eletromagnética

te e perpendicular às linhas do campo eletromagnético gerado (com sua direção paralela à direção na qual se encontra a antena) uma alternância do campo eletromagnético primário gerará correntes elétricas que tendem a fluir entre os extremos do condutor. Estas correntes induzidas geram um campo eletromagnético, secundário, que é perpendicular à direção do corpo (Fig. 3).

A propagação das ondas criadas a partir de um dipólo elétrico na superficie da Terra, envolve variações espaciais e temporais de origens diversas. Estas foram estudadas através de um monitoramento, efetuado no campo, do sinal transmitido (Valée et al., 1992) pois durante a sua propagação ocorrem fenômenos que geram ruídos e afetam o sinal recebido, ocasionando uma série de 


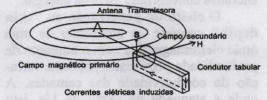

Figura 3 - Origem do campo eletromagnético secundário (adaptado de Phillips \& Richards, 1975).

interferências indesejáveis na recepção do sinal.

A técnica VLF tem sido empregada com sucesso em mapeamentos geológicos na determinação de zonas de falhas e fraturamentos, bem como em estudos de prospecção mineral (Paal, 1965, 1968; Phillips \& Richards, 1975), na prospecção de água subterrânea $(\mathrm{Pa}$ lacky et al., 1981; Poddar \& Rathor, 1983; Mcneil, 1991; Leite et al., 1992), em estudos ambientais (Slaine \& Greenhouse, 1982; Sinha \& Hayles, 1988) e geotécnicos (Ogilvy et al., 1991).

A principal vantagem que o método VLF apresenta em relação aos demais métodos, que se utilizam de campos artificiais, é que a antena transmissora (responsável em gerar o sinal) fica fixa dispensando desta forma cuidados com o transmissor, resultando assim em uma grande economia tanto em tempo quanto no número de pessoas envolvidas durante o processo de levantamento dos dados. Utiliza-se de antenas transmissoras distribuidas em vários locais do mundo, com alta potência de transmissão (entre 350 a $1000 \mathrm{~kW}$ ) e comprimentos de onda que variam entre 12 e $20 \mathrm{~km}$. Uma antena de transmissão VLF é efetivamente um extenso fio vertical.

A pontos situados a grandes distâncias da antena transmissora a onda gerada a partir da antena pode ser considerada como um onda plana e de intensidade constante.

Considerando-se as diferentes for- mas de medir os parâmetros de VLF, os levantamentos de campo para a elaboração deste trabalho foram feitos utilizando-se o modo inclinação do campo eletromagnético resultante. Em condições isentas de corpos (falhas contendo água, por exemplo), que possuam uma condutividade contrastante com a condutividade do meio onde o corpo se encontra encaixado, o campo medido é horizontal. Ao se aproximar de corpos que possuam contrastes de condutividade em relação ao meio encaixante, 0 campo eletromagnético sofre uma alteração, afastando-se da posição horizontal mudando de inclinação progressivamente, à medida que se aproxima, corta e ultrapassa o raio de influência gerado pelo corpo. O campo eletromagnético primário é aproximadamente paralelo às linhas de levantamento e normal ao corpo condutor 2D, onde se obtém o acoplamento máximo entre o condutor e as linhas de campo. O campo magnético primário não possui componente vertical na ausência de um condutor anômalo. Na presença de corpos condutores, o campo primário induz uma componente vertical secundária no campo, que interage com as heterogeneidades condutivas do meio, resultando em uma polarização elíptica no campo magnético total.

Na prática e, em geral, determinase o ângulo do "tilt" (inclinação) e a "ellipticity" (elipticidade) das componentes da elipse de polarização magnética no plano $x, z$ (Fig. 4).

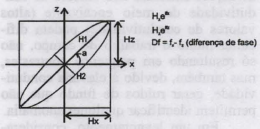

Figura 4 - Elipse magnética de polarização (adaptada de Saydam, 1981) 
O ângulo do "tilt" a é a inclinação do eixo maior da elipse em relação ao plano horizontal de polarização, e a "ellipticity" e é a razão entre o eixo menor e o eixo maior da elipse $(\mathrm{H} 2 / \mathrm{H} 1)$.

São basicamente três os fatores a serem considerados para que se possa realizar um estudo de prospecção geofisica utilizando o método VLF, sendo eles:

1. direção do levantamento;

2. espessura e resistividade da camada de cobertura; meios.

3. contraste de resistividade dos

1. A direção mais adequada para que seja realizado um levantamento de campo utilizando o método VLF é aquela na qual o levantamento é efetuado perpendicularmente ao corpo condutor, que deverá estar disposto de forma ortogonal às linhas de campo, ou seja, paralelo à linha que une o observador à antena de transmissão $\mathrm{e}$, caso não seja possível obter esta condição, a direção na qual o levantamento deverá ser realizado poderá variar, no máximo, de $45^{\circ}$ em relação à direção da estrutura.

2. A presença de camadas superficiais, cobrindo as estruturas objeto de investigação, atua durante o levantamento não como fonte de anomalia, mas sim como inibidor de sinal, caso elas forem condutivas ou muito espessas.

3. A resistividade do meio encaixante também pode gerar dificuldades no momento de execução dos trabalhos. Situações extremas nos valores de condutividade do meio encaixante (altos valores de condutividade) podem dificultar muito o trabalho de campo, não só resultando em pequenos contrastes, mas também, devido à elevada condutividade, gerar ruídos de fundo que não permitem identificar qualquer anomalia.

Em um levantamento, considerase como sendo a profundidade de investigação, a profundidade na qual se encontra concentrada $70 \%$ da energia.

$\mathrm{O}$ efeito de penetração ou "skin depth" consiste na atenuação de uma onda eletromagnética com o aumento da profundidade provocada por uma variação da condutividade das camadas. A onda é atenuada na razão de $1 / \mathrm{e}$, isto equivale a uma perda de energia aproximada de $37 \%$. A relação que permite calcular o grau de atenuação ou qual a profundidade máxima de investigacão, levando-se em consideração a resis tividade de um meio homogêneo, no qual o corpo condutor se encontra, é dada por:

$$
\delta=\left(\frac{2}{\varpi \mu \sigma}\right)^{1 / 2}
$$

onde: $\delta$ é a profundidade de penetração - efeito pelicular; e, $\sigma$ é a condutividade aparente do meio em mhos/m:

$$
\sigma=1 / \rho a
$$

após algumas aproximações temos:

$$
\delta=(\rho / f)^{1 / 2}
$$

onde: $\rho$ é a resistividade do meio encaixante; e, f é a frequiência da estação transmissora.

Através da equação acima pode-se construir-se a tabela abaixo (Tabela 1), que mostra que uma onda eletromagnética possui uma penetração que será tanto maior quanto mais resistivo for o meio no qual ela se propaga. Para o caso de prospecção VLF, o efeito não varia substancialmente considerando-se que as freqüências são baixas e o intervalo no qual se opera é pequeno.

\section{EQUIPAMENTOS DISPONIVEIS NO MERCADO}

Atualmente existem vários tipos de equipamentos capazes de efetuar um levantamento VLF. Existem também 
Tabela 1 - Variação da profundidade de investigação $\mathrm{em}$ função da resistividade do meio e da freqüência.

\begin{tabular}{lrrrrrrr} 
& \multicolumn{7}{c}{$\begin{array}{c}\text { Frequencias } \\
(\mathrm{Hz})\end{array}$} \\
$\begin{array}{l}\text { Resistividade } \\
\text { (Ohm.m) }\end{array}$ & 15000 & 17500 & $\begin{array}{c}20000 \\
22500 \\
\text { Profundidade } \\
(\mathrm{m})\end{array}$ & 25000 & 27500 & 30000 \\
0.0001 & 0,04 & 0,04 & 0,04 & 0,03 & 0,03 & 0,03 & 0,03 \\
0.01 & 0,41 & 0,38 & 0,35 & 0,33 & 0,32 & 0,30 & 0,29 \\
0.1 & 1,29 & 1,20 & 1,12 & 1,05 & 1,00 & 0,95 & 0,91 \\
1 & 4,08 & 3,78 & 3,54 & 3,33 & 3,16 & 3,02 & 2,89 \\
10 & 12,91 & 11,95 & 11,18 & 10,54 & 10,00 & 9,53 & 9,13 \\
100 & 40,82 & 37,80 & 35,36 & 33,33 & 31,62 & 30,15 & 28,87 \\
500 & 91,29 & 84,52 & 79,06 & 74,54 & 70,71 & 67,42 & 64,55 \\
1000 & 129,10 & 119,52 & 111,80 & 105,41 & 100,00 & 95,35 & 91,29 \\
5000 & 288,68 & 267,26 & 250,00 & 235,70 & 223,61 & 213,20 & 204,12 \\
10000 & 408.25 & 377.96 & 353.55 & 333.33 & 316.23 & 301.51 & 288.68
\end{tabular}

atualmente magnetômetros e gradiômetros acoplados a equipamentos VLF que podem, desta forma, ampliar ainda mais a quantidade de informações obtidas e diminuir as incertezas obtidas durante um levantamento e sua subsequente interpretação.

A necessidade de se acoplar num único sistema mais de um tipo de metodologia de investigação é consequiência do fato de muitas vezes ser necessário empregar-se mais de uma metodologia no campo, resultando assim em redução de tempo, conseqüentemente de custos de um levantamento.

Os aparelhos de VLF, que se encontram disponiveis no mercado, podem ser divididos em duas categorias: os que medem somente os parâmetros associados à elipse de polarização e, os que medem as diversas componentes do campo VLF total. Vale a pena lembrar que o conceito descrito para a elipse de polarização de uma onda eletromagnética é apenas um modo de representar o campo total.

A próxima geração de receptores VLF deverá apresentar uma tendência de efetuar medidas individuais das componentes do campo total, decompostos em suas partes real (em fase) e imaginária (fora de fase).
Os diferentes receptores existentes atualmente no mercado, utilizam para a medida do campo magnético total as componentes do campo eletromagnético. Nestes, os parâmetros equivalentes à elipse de polarização são apresentados de formas distintas através de um "display", onde podem ser visualizados os dados obtidos no levantamento, no momento em que está sendo realizado ou então submeterem os dados a um tratamento matemático mais refinado em um microcomputador.

O receptor VLF - EM mais citado nos trabalhos publicados desde 1971, é - fabricado pela GEONICS, que mede os parâmetros do campo eletromagnético total equivalentes à "ellipticity". Este receptor possui um dispositivo eletrônico que realiza a medida e registra os dados automaticamente, opera com frequiências entre 15 e $25 \mathrm{Khz}$.

$\mathrm{O}$ equipamento fabricado pela ABEM, modelo WADI, opera com freqüências de 15 a $30 \mathrm{kHz}$. Possui um rastreador de sinal que realiza a busca automática das antenas transmissoras de maior intensidade na direção em que o levantamento está sendo pretendido a ser efetuado no campo.

A visualização dos dados é realizada através de um "display" de cristal 
líquido onde os dados se apresentam pré-processados, através da aplicação de filtros.

O laboratório de geofísica do BRGM, desenvolveu a série SYSCAL de receptores VLF. Este receptor possui como particularidade o fato da antena receptora possuir três bobinas. Possui um módulo de pré-tratamento dos dados através de filtragem, realiza busca automática dos transmissores mais intensos e trabalha com frequêencias que variam de 10 a $30 \mathrm{kHz}$.

A SCINTREX, também possui o seu receptor VLF, conhecido como VLF-3. Atualmente lançou o GSM-19, um único receptor que pode operar, quando utilizado com seus respectivos acessórios, como magnetômetro, gradiômetro e VLF. Neste caso pode medir o campo VLF-EM, e quando acompanhado dos eletrodos capacitivos pode também efetuar as medidas de VLFEMR.

O equipamento utilizado para efetuar os levantamentos deste trabalho é fabricado pela ABEM, conhecido como WADI. Trata-se de um instrumento desenvolvido para localizar fraturas em zonas de rochas cristalinas, podendo estas estruturas serem verticais ou subverticais. Permite que os dados sejam descarregados diretamente em uma impressora ou que sejam transferidos para um micro computador para posterior tratamento. Mede a componente magnética do campo vertical induzido em relação à componente magnética do campo horizontal primário gerado pela antena transmissora. Seus resultados são expressos em porcentagem de campo em duas outras componentes, uma em fase (real) e outra fora de fase (imaginária).

A versatilidade e as opç̃̃es que o WADI oferecem durante um levantamento de campo são basicamente três:

- portabilidade do sistema - o WADI é um equipamento que fica posi- cionado na cintura do operador suspenso por um cinto.

- o equipamento possui um peso de aproximadamente $7 \mathrm{~kg}$;

- permite interpretar anomalias no momento em que o levantamento está sendo realizado.

$\mathrm{O}$ equipamento é dividido em três partes: unidade de antena, unidade analógica de processamento de sinal e computador.

A unidade antena (Fig. 5) é formada a partir de duas antenas compostas por núcleo de ferrite com um comprimento de 15 centímetros cada uma, enroladas por milhares de espiras, dispostas perpendicularmente, de modo que uma possa medir a componente horizontal e a componente vertical do campo.

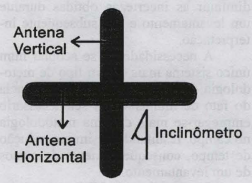

Figura 5 - Desenho esquemático da disposiçāo das antenas.

Neste conjunto existe também um inclinômetro de $0,2^{\circ}$ de precisão, acoplado à unidade de antena, que dispensa um nivelamento preciso da antena, pois o inclinômetro permite corrigir automaticamente, através de cálculos matemáticos, o erro de nível da antena, desde que essa correção não seja muito grande.

Desta forma os parâmetros do campo magnético medidos são três:

- Hy: a amplitude horizontal do campo magnético primário, na direçâo 
perpendicular à linha que une o observador à antena transmissora.

- Hx: a amplitude da componente do campo magnético secundário que está em fase com a componente horizontal.

- Hz: a amplitude da componente do campo magnético secundário que está fora de fase com a componente horizontal.

Os valores obtidos durante os levantamentos são calculados automaticamente pelo equipamento a partir de uma relação entre as duas componentes verticais e a componente horizontal do campo magnético.

$O$ módulo central deste equipamento é o que podemos identificar como sendo a unidade analógica de processamento de sinal. Esta unidade é reponsável pelo controle de todo o processo de leitura e aquisição dos dados, sendo composta basicamente por circuitos eletrônicos, processadores e amplificadores de sinal.

O computador acoplado à unidade analógica de processamento de sinal, possui um microprocessador que realiza todos os cálculos e gerencia a memória onde ficam armazenados todos os dados (Fig. 6).

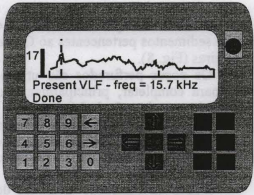

Figura 6 - Desenho esquemático da unidade de processamento.

Possibilita através de teclas alfa- numéricas entrar com a direção dos perfis, orientá-los de acordo com um sistema de referência próprio do equipamento.

Os resultados dos dados coletados são expressos em porcentagem (\%) de campo, obtendo-se duas leituras: uma leitura da componente real (ou em fase) e uma leitura da componente imaginária (ou em quadratura).

Pode-se controlar ainda :

- o intervalo entre cada ponto de medida;

- a antena transmissora a ser selecionada;

- a representação dos dados dos perfis na tela de cristal líquido, com ou sem aplicação de filtragem.

Este módulo possui ainda uma opção de interpretação aproximada das estruturas eventualmente detectadas, que pode ser utilizada no campo durante o levantamento, sem que seja necessária a transferência dos dados obtidos para outro computador com maior capacidade de processamento.

\section{ÁREAS DE TESTES}

\section{Estado da Bahia}

Com o objetivo de calibrar a metodologia, foram realizados levantamentos no interior da Bahia em algumas localidades onde as condições básicas de aplicabilidade do método eram satisfeitas (delgado manto de intemperismo ou cobertura sedimentar de pequena espessura).

As localidades investigadas apresentavam a existência de poços perfurados e as informações referentes aos perfis litológicos e testes de vazão estavam disponiveis.

Os poços utilizados para a pesquisa possuiam características próprias e diversas, sendo que:

- três poços, perfurados nas localidades de Riacho dos Pilões, Represa e Barracas, continham água doce; 
- um poço, situado no $\mathrm{km} 39$ da rodovia que liga a localidade de Pedras Altas à localidade de Barraca, continha água salgada;

- um poço, localizado em Riacho da Onça, perfurado até a profundidade de 90 metros foi considerado como sendo seco.

A área de estudo localiza-se entre as seguintes coordenadas geográficas: $11^{\circ} 00^{\prime}-11^{\circ} 30^{\prime}$ Latitude Sul e $39^{\circ} 30^{\prime}$ $40^{\circ} 10^{\prime}$ Longitude Oeste.

Geologicamente estas áreas situam-se sobre a Formação Capim Grosso. O embasamento cristalino é formado por: complexo granulítico, metatexitos e gnaisses pertencentes ao Grupo PréEspinhaço (Fig. 7).

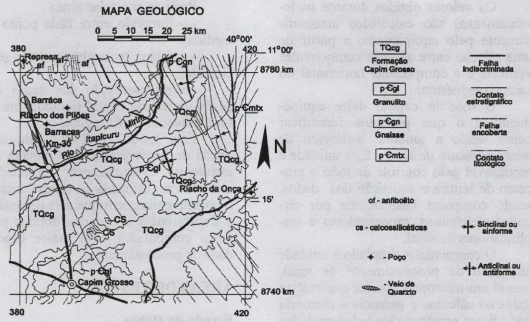

Figura 7 - Mapa geológico da área situada no Estado da Bahia (DNPM = Escala 1:250.000).

\section{Ceará - Município de Maracanaú}

O Município de Maracanaú, situado a SW da cidade de Fortaleza, possui uma área de aproximadamente $94 \mathrm{~km}^{2}$. Em 1990 possuía cerca de 96.740 habitantes na zona urbana e 5.140 habitantes na zona rural.

$\mathrm{O}$ acesso ao municipio se faz partindo-se de Fortaleza, pela rodovia CE021. Está situado a aproximadamente $50 \mathrm{~km}$ de distância da capital do Estado. Encontra-se situado entre as seguintes coordenadas geográficas: $3^{\circ} 45^{\prime}-4^{\circ} \mathrm{La}$ titude Sul e $38^{\circ} 30^{\prime}-38^{\circ} 45^{\prime}$ Longitude Oeste.

Geologicamente está situado so- bre rochas do Complexo Nordestino e sobre sedimentos pertencentes ao Grupo Barreiras (Fig. 8).

Os poços perfurados são utilizados para completar, principalmente, o abastecimento da sede do Município.

$\mathrm{Na}$ região de Maracanaú ocorrem sedimentos do Grupo Barreiras e rochas metamórficas e ígneas pertencentes ao Complexo Tamboril-Santa Quitéria.

Dados da Fundação Cearense de Meteorologia e Recursos Hidricos FUNCEME, indicam a existência de 84 poços perfurados nas áreas próximas ao município, que apresentam uma profundidade máxima do embasamento de 72 


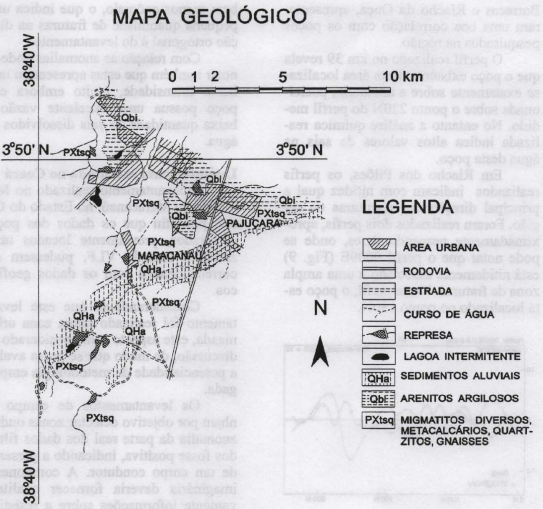

Figura 8 - Mapa Geológico da Região de Maracanaú escala: 1:100.000 (adaptado de DNPM, 1983).

metros e mínima a 3 metros, com vazões de até $7.900 \mathrm{l} / \mathrm{h}$.

O Munícipio de Maracanaú, propriamente dito, possui um total de 86 poços sendo 4 perfurados sobre o Grupo Barreiras, com vazão de $30.150 \mathrm{~V}$ dia para um período de 18 horas de bombeamento. A vazão média dos poços perfurados nos sedimentos é de $1.675 \mathrm{l} / \mathrm{h}$.

Os poços perfurados no cristalino (rochas metamórficas e granitos) fornecem ao município um total de 27.540 $1 / d$ para um período de 18 horas de bombeamento, o que correponde a uma vazão média de $1.530 \mathrm{l} / \mathrm{h}$.

Muitos poços apresentam água com uma alta concentração de sais, tornando-se inadequados ao consumo humano.

A causa da salinização em áreas de rochas cristalinas do Nordeste do Brasil, segundo Santiago (1984), é devida à elevada evaporação das águas superficiais concentrando-se de sais, e estas águas recarregarem os aqüiferos subterrâneos.

\section{RESULTADOS OBTIDOS}

\section{Levantamento executado na Bahia}

Os levantamentos realizados no Estado da Bahia, nas localidades de 
Barracas e Riacho da Onça, apresentaram uma boa correlação com os poços pesquisados na região.

O perfil realizado no $\mathrm{km} 39$ revela que o poço existente nesta área localizase exatamente sobre a anomalia, posicionada sobre o ponto $220 \mathrm{~N}$ do perfil medido. No entanto a análise química realizada indica altos valores de sais na água deste poço.

Em Riacho dos Pilões, os perfis realizados indicam com nitidez qual a principal direção das estruturas da região. Foram realizados dois perfis, aproximadamente perpendiculares, onde se pode notar que o perfil $0009 \mathrm{E}$ (Fig. 9) está nitidamente associado a uma ampla zona de fraturas. Neste perfil, o poço está localizado no ponto $180 \mathrm{~N}$.
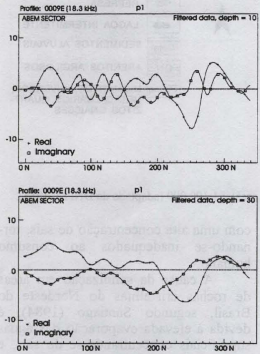

Figura 9 - Perfil 0009E realizado em Riacho dos Piloes - Ba.

No perfil $0010 \mathrm{E}$, também realizado nesta área, nota-se um comportamento diferente do padrão do perfil 0009E, ou seja, este perfil apresenta-se bem menos anômalo, o que indica uma pequena quantidade de fraturas na direção ortogonal à do levantamento.

Com relação às anomalias pode-se notar também que estas apresentam uma baixa intensidade, muito embora este poço possua uma excelente vazão e baixa quantidade de sais dissolvidos na água.

\section{Levantamento executado no Ceará}

$\mathrm{O}$ levantamento realizado no $\mathrm{Mu}$ nicipio de Maracanaú, no Estado do Ceará, permitiu que os dados dos poços perfurados, previamente locados utilizando o método VLF, pudessem ser correlacionados com os dados geofisicos.

Considerando-se que este levantamento foi realizado numa zona urbanizada, este aspecto será considerado na discussão, de modo que se possa avaliar a potencialidade da metodologia empregada.

Os levantamentos de campo tinham por objetivo detectar zonas onde a anomalia da parte real dos dados filtrados fosse positiva, indicando a presença de um corpo condutor. A componente imaginária deveria fornecer qualitativamente informações sobre a resistividade do corpo, ou seja, uma anomalia obtida na componente imaginária, após filtragem, conforme descrito por Karous \& Hjelt (1983), que assumisse valores muito negativos ou muito positivos, indicaria a presença de corpos condutores (zonas de fraturas preenchidas por água salgada, zonas mineralizadas).

Se a anomalia da parte imaginária ficar em torno de zero ou se ela for pouco positiva, deverão ser encontrados corpos com resistividade elevada, e neste caso, corresponder à uma zona de fratura contendo água com um baixo teor de sais. Em geral, é muito raro de corpos condutores produzirem um efeito semelhante a este.

O sinal positivo ou negativo das 
anomalias obtidas na parte imaginária depende muito da espessura e da resistividade da cobertura sedimentar ou do manto de intemperismo.

Baseando-se nestas informações (ABEM), ao longo deste estudo, esperava-se diferenciar as zonas fraturadas contendo água doce daquelas preenchidas por água salgada. No entanto, durante a interpretação dos dados obtidos no levantamento efetuado no Município de Maracanaú, este fato não ocorreu como se pode notar nos perfis 0014, 0030, 0032 e 0039 (Fig. 10), onde foram obtidas anomalias tanto na parte real quanto na parte imaginária, praticamente de mesma intensidade, o que corresponderia a fraturas preenchidas por água doce, quando deveriam corresponder à água salgada.
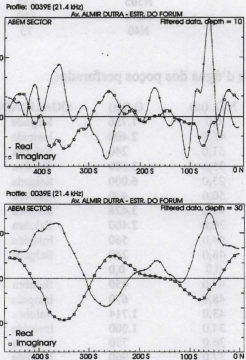

Figura 10 - Perfil 0039W realizado no Município de Maracanaú - CE

Foram encontrados pontos anômalos nos perfis 0002, 0009, 0027 e
0041 (Fig. 11) posteriormente perfurados, possuindo grandes anomalias na componente real e praticamente nulas ou então pouco positivas na componente imaginária, que revelaram a presença de água salgada, quando deveriam corresponder à água doce. Este fenômeno provavelmente seja decorrente do fato deste levantamento ter sido realizado em uma zona urbanizada onde as fontes de interferências eram freqüentes.
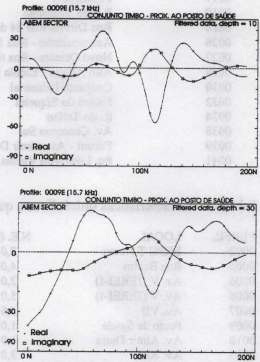

Figura 11 - Perfil 0009E realizado no Municipio de Maracanaú $-\mathrm{CE}$.

Os poços, que foram locados durante a campanha geofisica realizada neste município, foram perfurados imediatamente após o tratamento dos dados obtidos no campo.

As locações bem como seus resultados estão dispostos nas Tabelas $2 \mathrm{e}$ 3.

Os dados das propriedades hidráulicas, obtidos através dos testes de 
Tabela 2 - Número do perfil, local, direção do levantamento e locação de cada poço.

$\begin{array}{llcc}\text { PERFIL } & \text { LOCAL } & \text { DIREÇÃo } & \text { LOCAÇ̃̃o } \\ 0002 & \text { Grupo Escolar Tancredo Neves } & \text { NE } & 280 \\ 0005 & \text { Rua Belém } & \text { N250 } & 350 \\ 0006 & \text { Av. V - Jereissati - I } & \text { N250 } & 30 \\ 0006 & \text { Av. V - Jereissati - I } & \text { N250 } & 440 \\ 0007 & \text { Av. VII } & \text { N250 } & 165 \\ 0009 & \text { Posto de Saúde } & \text { N325 } & 65 \\ 0010 & \text { Av. Almir Dutra } & \text { N210 } & 400 \\ 0013 & \text { Av. XIII - Vila das Flores } & \text { N220 } & 330 \\ 0014 & \text { R. Capitäo Valdemar de Lima } & \text { N200 } & 560 \\ 0015 & \text { Liceu - Av. V - Jereissati -2 } & \text { N195 } & 220 \\ 0017 & \text { FEBENCE } & \text { N280 } & 370 \\ 0019 & \text { R. São Sebastião } & \text { N280 } & 115 \\ 0024 & \text { Rua Direita/Rua 24 de maio } & \text { N200 } & 335 \\ 0026 & \text { Acaracuzinho - Rua 108 } & \text { N200 } & 222 \\ 0027 & \text { Novo Oriente - Rua 6 } & \text { N295 } & 170 \\ 0029 & \text { Alto Alegre - Escola Estadual } & \text { N235 } & 310 \\ 0030 & \text { Conjunto Industrial } & \text { N45 } & 340 \\ 0032 & \text { Bairo do Siqueira } & \text { N20 } & 165 \\ 0034 & \text { R. do Trilho } & \text { N305 } & 270 \\ 0038 & \text { Av. Contorno Sul } & \text { N295 } & 455 \\ 0039 & \text { Forum - Av. Almir Dutra } & \text { N40 } & 370 \\ 0041 & \text { Pq. Louzardo Vianna } & & 75\end{array}$

Tabela 3 - Características hidráulicas e qualidade d'água dos poços perfurados.

$\begin{array}{llccrc}\text { PERFIL } & \text { LOCAL } & \text { N.E. }(\mathrm{m}) & \text { N.D. }(\mathrm{m}) & \text { Q }(\mathrm{lh}) & \text { QUALIDADE } \\ 0002 & \text { EEPG T.Neves } & 2,0 & 6,0 & 1.756 & \text { Salgada } \\ 0005 & \text { Rua Belém } & 4,0 & 45,0 & 2.400 & \text { Insípida } \\ 0006 & \text { Av. V (JEREI-I) } & 2,0 & 51,0 & 240 & \text { Salobra } \\ 0006 & \text { Av. V (JEREI-I) } & 5,0 & 35,0 & 3.600 & \text { Salobra } \\ 0007 & \text { Av. VII } & 3,0 & 23,0 & 6.000 & \text { Salgada } \\ 0009 & \text { Posto de Saúde } & 1,0 & 50,0 & 430 & \text { Salobra } \\ 0010 & \text { Av. Almir Dutra } & 1,0 & 40,0 & 3.428 & \text { Salgada } \\ 0013 & \text { Av. XIII } & 3,0 & 30,0 & 2.400 & \text { Salobra } \\ 0014 & \text { R. Cap. Valdemar } & 7,0 & 44,0 & 560 & \text { Insípida } \\ 0015 & \text { Av. V* JEREI-II } & 2,0 & 48,0 & 240 & \text { Salgada } \\ 0017 & \text { FEBENCE } & 0,0 & 0,0 & 0,0 & \\ 0019 & \text { Rua São Sebastiåo } & 5,0 & 47,0 & 450 & \text { Salobra } \\ 0024 & \text { Rua Direita } & 9,0 & 48,0 & 670 & \text { Insípida } \\ 0026 & \text { Conj. Acaracuzinho } & 4,0 & 43,0 & 1.714 & \text { Salobra } \\ 0027 & \text { Rua 6 - N.Oriente } & 4,0 & 34,0 & 1.000 & \text { Insípida } \\ 0029 & \text { Alto Alegre } & 3,0 & 36,0 & 750 & \text { Salgada } \\ 0030 & \text { Conjunto Industrial } & 1,0 & 37,0 & 960 & \text { Insipida } \\ 0032 & \text { Bairro do Siqueira } & 6,0 & 32,0 & 600 & \text { Insípida } \\ 0034 & \text { Rua do Trilho } & 1,0 & 29,0 & 680 & \text { Salobra } \\ 0038 & \text { Av. Contorno Sul } & 4,0 & 48,0 & 500 & \text { Salobra } \\ 0039 & \text { Av. Almir Dutra } & 3,0 & 46,0 & 200 & \text { Insípida } \\ 0041 & \text { Pq. Louzardo Viana } & 0,0 & 0,0 & 0,0 & \end{array}$


bombeamento realizados em cada poço. Considerando a forma como foram obtidos, não inspiram muita confiança, e desta forma comprometem o resultado.

A metodologia respondeu muito bem às expectativas, pois neste municipio, dos 23 poços perfurados, somente 2 deles foram considerados secos, apesar de terem sido encontradas fraturas durante a sua perfuração.

Não se pode no entanto deixar de levar em consideração o fato de que o levantamento realizado foi efetuado totalmente dentro de uma zona urbanizada, possuindo desta forma um ruído praticamente constante em todos os perfis, causados principalmente por redes elétricas, tanto aéreas quanto enterradas.

A interpretação dos dados foi realizada de forma qualitativa utilizando os perfis de caminhamento VLF e as pseudo-secções de densidade de corrente obtidas através do método de filtragem dos dados desenvolvidos por Karous \& Hjelt (1983).

\section{CONCLUSÕES E RECOMENDA- ÇÕ̂ES}

A geofisica revelou-se como semdo uma importante ferramenta no auxilio da locação de poços tubulares profundos em regiões cristalinas. Não obstante os seus bons resultados, a geofisica aplicada jamais poderá prescendir de informações obtidas através da geologia, fotogeologia e informações de carácter hidrogeológico da área.

O método VLF de exploração geofísica é bem aplicável às condições geológicas encontradas no Estado do Ceará, ou seja, zonas de rochas cristalinas subaflorantes com coberturas de espessuras entre 1 e 10 metros. Nos casos em que as coberturas possuem espessuras entre 10 a 20 metros, a metodologia é menos eficaz pois o sinal é consideravelmente atenuado.
Em áreas urbanizadas como na presença de redes elétricas, a metodologia responde relativamente bem, embora este tipo de interferência possa causar distorções nos dados. Isto deve ser considerado como sendo um dos principais fatores que causaram erros na interpretação dos dados e consequiente locação dos poços no Município de Maracanaú. Estes erros na locação dos poços, por sua vez, se traduzem nas baixas vazões dos poços, inferiores ao interpretado e esperado. Este tipo de interferência amplifica os dados da componente real e afeta também os dados da componente imaginária, responsáveis pela informação sobre a resistividade dos corpos.

Embora tenha ocorrido este tipo de interferência nos dados, a média de acerto na identificação das zonas fraturadas foi de $100 \%$ conforme revelaram os dados obtidos pela perfuração dos poços.

$\mathrm{O}$ que se notou durante toda a etapa de coleta dos dados é que a metodologia VLF quando utilizada dentro de zonas urbanizadas, como foi o caso do levantamento efetuado no Município de Maracanaú, apresenta valores de anomalias relativamente altos.

A vazão média dos poços já existentes na área era de $1530 \mathrm{l} / \mathrm{h}$ enquanto os locados através da utilização do método VLF e posteriormente perfurados, é de aproximadamente $1297 \mathrm{l} / \mathrm{h}$.

Deve-se, entretanto, levar em consideração que o número de poços existentes no município é significativamente maior do que os locados através do método VLF. Este tipo de comparação pode assim causar um certo mascaramento quanto à eficácia da metodologia.

A partir de uma análise dos resultados obtidos, pode-se notar (Gráfico 1) que o levantamento utilizando o método VLF possibilitou um aumento em porcentagem de poços com vazōes 


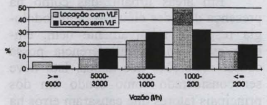

Gráfico 1 - Comparaçăo entre as vazóes de poços perfurados precedidos ou não por levantamentos VLF.

acima de $5.000 \mathrm{l} / \mathrm{h}$ e em poços com vazões entre $201 \mathrm{e} 1.000 \mathrm{l} / \mathrm{h}$, enquanto que diminuiu o número de poços com vazões entre 0 e $200 \mathrm{l} / \mathrm{h}$.

As vazões dos poços perfurados no Município de Maracanaú apresentam-se baixas devido à provável locação dos poços não em pontos ideais decorrentes da existência dos seguintes fatores limitantes:

- este levantamento foi efetuado no interior de uma zona urbanizada onde há limitações no espaço físico para a realização dos perfis, bem como na locação dos pontos escolhidos para serem perfurados, pois, ora a anomalia não estava localizada em área pública, ora estava situada no meio de uma rua.

- a realização de um levantamento em zona urbanizada gera, como pode ser observado na Figura 12, a amplificação do sinal e conseqüentemente durante o levantamento obter-se anomalias mais intensas, interpretandoas como fruto de estruturas de porte relativamente pequeno.

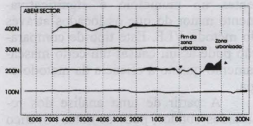

Figura 12 - Amplificação das anomalias em zonas urbanizadas junto a linhas de alta tensåo.
- a salinidade da água dos poços perfurados, pode causar uma anomalia mais condutiva e intensa, na presença de interferências provocadas pela rede elétrica em zonas urbanizadas.

Os fatores acima mencionados, atuando conjuntamente, afetam os dados de forma considerável, pois existem ao mesmo tempo duas fontes geradoras de anomalias atuando sobre os dados.

As vazões nem sempre são mais elevadas pelo fato de muitas vezes não ser possivel perfurar-se no local considerado como ideal, com base nos levantamentos geofísicos, dadas às limitações impostas pelas condições locais existentes (centro de uma rua, junto à uma edificação, sob linha de alta tensão, etc.).

O trabalho realizado no campo com os micro computadores é de suma importância, pois facilita a execução deste tipo de levantamento, tornando-o barato e simples.

Quanto à qualidade das águas subterrâneas a serem exploradas, talvez seja possível obter previsão, se os levantamentos forem efetuados em um grande número de áreas livres de qualquer interferência de origem antrópica (como por exemplo redes de eletricidade) e os dados geofisicos obtidos forem correlacionados com dados de análises químicas das águas obtidas nos poços ai perfurados.

A utilização do método geofísico do VLF apresentou resultados, que minimizaram os erros ocorridos durante o processo de locação de poços tubulares profundos perfurados para a explotação de água subterrânea.

Este tipo de levantamento gerou economia na região, mesmo considerando-se as baixas vazões obtidas nos poços perfurados, pois o custo médio de cada poço com 60 metros de profundidade é de aproximadamente US\$7.000. 


\section{REFERÊNCIAS BIBLIOGRÁFICAS}

$A B E M$. Interpretation guide - theory, practice and case stories for WADI operators.

BRAGA, A.P.G.; PASSOS, C.A.B.; FRANÇA, J.B. (1977) Projeto Fortaleza: relatório final. DNPM/ CPRM. 342p.

BRITO NEVES, B.B. (1975) Regionalização tectônica do pré-cambriano nordestino. São Paulo, 198p. (Tese Doutorado) - Instituto de Geociências, Universidade de São Paulo.

DNPM - Departamento Nacional de Produção Mineral (1963) Reconhecimento fotogeológico da região nordeste do Brasil: Folhas SA24O, SA24U, SA24V e SB24C. Escala $1: 250.000$.

KAROUS, M.; HJELT, S.E. (1983) Linear filtering of VLF dip-angle measurements. Geophysical Prospecting, v.31, p. 782-794.

LEITE, C.E.S.; ANDRADE, F.C.M.; NETO, P.S.; CORDEIRO, W. (1992) Prospecção hidrogeológica em rochas cristalinas utilizando ondas "VLF". In: SIMPÓSIO DE RECURSOS HIDRICOS DO NORDESTE. Anais. v.2, p.297-306.

MCNEILL, J.D. (1991) Advances in eletromagnetics methods for groudwater studies. Geoexploration, v.27, p. $65-80$.

OGILVY, R.D.; LEE, A.C. (1991) Interpretation of VLF-EM in phase data using current density pseudoecctions. Geophysical Exploration, v.39, p.567-580.

OGILVY, R.D.; CUADRA, A.; JACKSON, P.D.; MONTE, J.L. (1991) Detection of filled drainage gallery by the VLF resistivity method. Geophysical Prospecting, v.39, p.845-859.

PAAL, G. (1965) Ore prospecting based on VLF - radiosignals. Geoexploration, n.3, p.139-147.
PAAL, G. (1968) Very low frequency measurements in northern Sweden. Geoexploration, v.6, p.141-149.

PALACKY, G.J.; RITSEMA, I.L.; JONG, S.J. (1981) Electromagnetic prospecting for groundwater in precambrian terrains in the Republic of Upper Volta. Gephysical Prospecting v. 29, p. $932-955$.

PATERSON, N.R.; RONKA, V. (1971) Five years of surveying with the very low frequency electromagnetics method. Geoexploration, v.9, p.726.

PODDAR, M.; RATHOR, B.S. (1983) VLF survey of weathered layer in Southern India. Geophysical Prospecting, v.31, p.524-537.

SANTIAGO, M.M.F. (1984) Mecanismos de salinizaçāo em regiōes semi-áridas: estudo dos açudes $\mathrm{Pe}$ reira de Miranda e Caxitoré no Ceará. São Paulo, 176p. (Tese Doutorado) - Instituto de Geociências, Universidade de São Paulo.

SANTOS, J.P.; AZEVEDO, S.G.; MISTRETTA, G. (1984) Novos aspectos da salinização de águas subterrâneas no cristalino do Rio Grande do Norte. São Paulo, IPT. Contribuição Técnica, n.314, p.1-27.

SAYDAM, A.S. (1981) Very low frequency electromagnetic interpretation using tilt angle and ellipticity measurements. Geophysics, v.46, n. 11, p.1594-1605.

SLAINE, D.D. (1982) Case studies of geophysical contaminant mapping at several waste disposal sites. In: NATIONAL SYMPOSIUM ON AQUIFER RESTORATION AND GROUNDWATER MONITORING, 2., Worthington, 1982. Proceedings, United States, National water well Association, p.299-315.

SINHA, A.K.; HAYLES, G.H. (1988) Experiences with a local loop VLF transmiter for geological studies in canadian nuclear fuel waste man- 
agement program. Geoexploration, v. 25, p. $37-50$.

SUDENE - Superintendência de Desenvolvimento do Nordeste (1971) Carta Topográfica: região nordeste do Brasi 1 - Folha Fortaleza. Escala
1:100.000.

VALLÉE, M.A.; CHOUTEAU, M.; PALACKY, G.J. (1992) Effect of temporal and spatial variations of the primary signal on VLF total fields survey. Geophysics, v. 57, p.97-105.

R.M.Marques - Instituto de Geociências, Universidade de São Paulo, Caixa Postal 11.348, CEP 05422-970, São Paulo, SP, Brasil. 